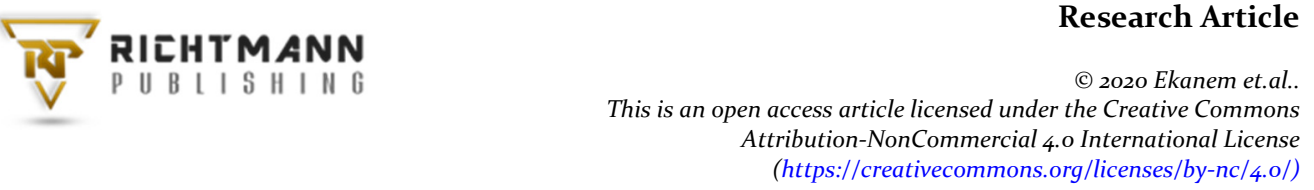

Received: 28 October 2019 / Revised: 11 December 2019 / Accepted: 23 December 2019 / Published: 10 January 2020

\title{
University Output Soft Skills at Workplace in Blue Economy Strategy for Sustainable Development in Cross River State, Nigeria
}

\author{
Ekpenyong E. Ekanem
}

\author{
Dr. Mrs. Comfort R. Etor \\ Dr. Mrs. Nse N. Ukpong \\ Department of Educational Management \\ Faculty of Education, University of Calabar, \\ P.M.B. 1115, Calabar, Cross River State, Nigeria
}

Doi: 10.36941/mjss-2020-0oo8

\begin{abstract}
This study investigated university output soft skills and blue economy strategy as mechanisms for sustainable development in Cross River State of Nigeria. The study was a descriptive survey research design. The population included all university graduate workers in sea ports in the state. A purposive sampling techniques was used to select 250 respondents from the port locations. The instrument designated 'Soft Skills In Blue Economy Strategy Questionnaire (SSIBESQ)' was designed to collect data for the study. The instrument was validated and had a reliability co-efficient of 0.872 . The data collected were analyzed using frequency counts and percentage score. The study revealed that university output soft skills were beneficiary to the graduate workers economically and encouraged multitasking in human and material resources for sustainable development of Cross River State, Nigeria. Blue economy strategy, through a dynamic environmental sustainable principles, assisted the university output at workplace. This included to boost new employment, innovation and growth in marine production and other port industries, thereby improving the state economic stand. Some of the recommendations made were: universities should give more attention to soft skills development, government should support policies on university output soft skills and blue economy strategy as sine-qua-non for utilization of business opportunities and economic development in the state.
\end{abstract}

Keywords: Blue, economy, university, skills, development

\section{Introduction}

The uncertain economic times in most developing nations of the world may be occasioned by the rapidly changing labour market-driven fluid and global economy. This could be the case in Nigeria facing the period of economic contraction with sluggish recovery and volatility in global oil prices (Ekpo, 2016). The state of the economy in Nigeria creates the need for embracing a blue economy strategy for blue growth. The strategy in Cross River State of Nigeria may structurally and effectively transform, especially the service and logistic sectors of the economy. It seems to be an urgent call for university output at workplace to possess some technical skills taught as well as a host of basic skills for greater productive outcome across job titles. Therefore, this research is anchored on a clarion call 
for all stakeholders in the state to chart ways out of the declining economy toward improved standard of living of the average people.

The call for acquisition of soft skills at workplace suggests a shift of the university system role from knowledge transfer to knowledge filter for re-orientation, as a trust in education. This is because competence graduates are needed from the university system with employability skills (Friendman, 2006). In Ekanem (2015), significant number of people in Cross River State, Nigeria are unskilled and unemployed despite the existence of the two public universities in the state. The universities seem not to positively affect the people of the state who are the main actors in the economy, hence poor standard of living in the state (UNDP, 2010). The university education policies tend not to materially support principles for meeting human development goals while sustaining the ability to meet future generation needs in Cross River State, Nigeria.

University education in the state plays an important role in determining the level and distribution of income in the society, productivity and economic growth. The structural transformation of the state goes beyond the roles of providing education and enabling social environment to correcting market failure for sustainability. In this study, sustainable development is define as a deliberate and systematic policy programme of ensuring survival and continuous improvement of the state of social, economic and political necessities that are imperative for the enjoyment of good life now without constituting a denial for the capacity of being able to enjoy the same benefit by generations yet unborn. This is achievable through judicious and careful use of global resources for improvement of the standards of living, job creation and youth empowerment (Obanya (2013).

Government in Nigeria developed education policies in line with neo-liberal economic strategies but without sincere political support on existing framework to revitalize environmentally sustainable programmes. One of such programmes seem to be the blue economy strategy. It is a marine economy development approach which provides opportunities economically to learners for learning environmental concepts through education and training. University education is a vital tool in providing higher manpower requirement for economic, political and social development of a nation. As such, it is a prerequisite for economic development in terms of specialized knowledge and skill acquisition (Ekanem, 2015). It is in that light which university education acclaim to be the most important instrument of social change and social mobility in the society.

Proper quality management of the university education can be said to be the only way university output can apply the education to achieve goals of transforming the society. It seems that university education has not sufficiently empowered university products to be self reliant and useful members of the society towards sustainable development. There have been increasing number of graduates from universities who roam the streets in Nigeria seeking for employment. This points to the fact that skills acquired by the university output cannot match with the labour market demand. Hence, universities in Cross River State, Nigeria tend to fail in being repositories of fundamental knowledge and basic skills because the natural realities are not incorporated in the education system. The university output at workplace are not committed to modern ideology and employability skills (Vishal, 2016). Nevertheless, re-engineering of the university system may ensure high level skills and creative spirit.

Soft skills are said to be the most critical skills in the current global job market especially in a fast moved era of technology. It incorporates all aspects of generic skills which include cognitive elements associated with non-academic skills. In this study it involves such skills as entrepreneurship skills, life-long learning skills and leadership skills which enable individuals to adjust to life challenges (Wilken, 2015). As such, the determination of specific roles of soft skills involve reorientation of education in ensuring quality education for sustainability.

The theoretical framework of this study is derived from needs assessment evaluation model by Gall, Borg and Gall in 1996. The theory states that discrepancy between an existing sets of conditions, and a desired sets of conditions; equals a need. In this study the researcher express an anomaly between an existing set of skills and a desired skills (soft skills). The statement of need is a judgment 
about the merit of university policies and programmes. The framework, being a quantitative approach, enables the researcher to measure the precise extent of the discrepancy between the existing skills acquired and the desired soft skills at workplace in Blue Economy Strategy (BES) in Cross River State, Nigeria.

A conceptual model derived from the theoretical framework stated can be used to illustrate the relationship among the concepts of the study as conjectured in figure 1 .

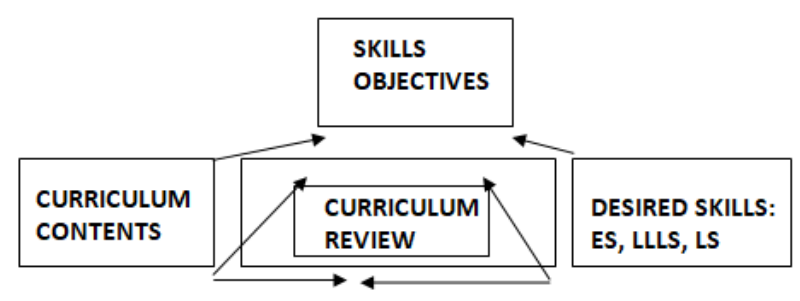

Figure 1: A relationship of curriculum contents, skill objectives and desired skills in university reorientation.

Source: Adapted from Uwadileke, O. 2015. African Journal of Theory and Practice in Education p.93

In the schematic model, there is a link among curriculum contents in the university education programmes, the skills objectives in the curriculum theme and the need to infuse into subsequent curriculum review for value reorientation. The desired skills are represented in this study by three employability skills of Entrepreneurship Skills (ES), Life-Long Learning Skills (LLLS) and Leadership Skills (LS). The broad utilization of these soft skills by the university graduates across job titles and industries, indicate an indispensable role they play in knowledge creation in blue economy strategy for a virile economy (UNDP, 2012). This is basically because soft skills describes personal attributes of the workers that indicate high level emotional intelligence, unlike hard skills.

The significant of this investigation will be seen as an inspiration for universities to be committed to quality attainment in knowledge-management among other potential benefits. The government will pay attention to university education development and blue economy strategy. Educational managers, students and parents will equally find the study useful as universities are prime targets of efforts to the production of high manpower in the economy.

The study is particularly important to scholars since it examines the various soft skills and blue economy strategy for sustainable development in order to foster corporate culture and improve standard of living of individuals in the state. The scope of the study is delimited to university output soft skills at workplace interms of entrepreneurship skills, life-long learning and leadership skills. The study focused on the blue economy strategy for job creation, youth empowerment and improved standard of living of individuals.

Based on value re-orientation of the university education, this paper sets out to find out university output soft skills at workplace in blue economy strategy so as to sustain development in Cross River State, Nigeria. Specifically, the objective of this study is to investigate entrepreneurship skills, life-long skills and leadership skills in blue economy strategy. It also examines the extent of government involvement in soft skills development and blue economy strategy for youth empowerment, job creation and improved standard of living in Cross River State, Nigeria.

\section{Statement of the Problem}

The attendant problem of dearth in knowledge creation has been a matter of concern to stakeholders in education. It was observed that graduates of universities in Cross River State, Nigeria lacked soft skills at workplace due to failure in renaissance of knowledge. This posed a serious challenge to 
economic growth and sustainable development in the state. The universities seem to fail in their mandate of producing quality high manpowerwith basic skills in specific job areas for sustainable development as stated in National Policy on Education 2013. This may resolve in social problems and failure in leap frogging selected areas of growth and development in the state. Soft skills such as entrepreneurship skills, life-long learning and leadership skills were considered most critical in global market in this study. These skills tend to fail to synthesize disparate ideas especially in blue economy strategy. The question is, could the university output soft skills in workplace in blue economy strategy empower the economy to grow and sustain development in Cross River State, Nigeria? This is in a sense that no matter how laudable university programmes may be, if the university output fails to show creativity and multitasking at workplace, the educational output may not be labour-market driven for sustainable development.

It was a common observation that university system favoured hard skills acquisition at the expense of soft skills. Hence, the attitude of university graduates at workplace lacked the culture that related to and interacted with others in organization for productivity. In the blue economy, they could not address challenges of resource scarcity and waste disposal for the enhancement of human welfare in the state. There was also a challenge of poor political support by government with sustainable maritime policy framework to nurture expectations such as job creation, environmental sustainability and capital accommodation. The state was seemingly inelastic to global changes in blue economy revolution. The above observation prompted the researcher to find out whether or not university output soft skills at workplace in blue economy strategy could be used to sustain development in Cross River State, Nigeria if properly managed.

\section{Research Questions}

In addressing this problem, the following research questions were raised in order to achieve the aims of this study.

1. In what ways do soft skills at workplace in blue economy strategy empower university output economically?

2. How does blue economy strategy contributes to the sustainable development in Cross River State, Nigeria?

3. Does government contribution of university output soft skills impact economically on blue economy strategy?

\section{Methodology}

The research design for this study was a descriptive survey type. The area of study was Cross River State, Nigeria. It is one of the states in south-south geopolitical zone of the nation. The state has two public universities and one private university. It is also a home of eastern ports complex and Calabar free port zone while its inhabitants occupation include fishing, trading and farming. Effective management of basic skills of university graduate workers in the blue economy may sustain development in Cross River State, Nigeria. The population included the university graduate worker in the sea ports located in the state. A purposive sampling technique was used to select 250 university graduate workers in Calabar ports as sample size.

The respondents responded to a researcher constructed questionnaire titled 'Soft Skills In Blue Economy Strategy Questionnaire (SSIBESQ)'. The SSIBESQ consisted of three sections on assessment of university output soft skills, blue-economy and government for sustainable development in Cross River State, Nigeria. A face validity of the instrument was done by subjecting it to the critique of experts in Educational measurement and Educational management in University of Calabar, Calabar. The reliability test was determined to be 0.875 using Cronbatch Alpha reliability technique. The instrument was reliable for successful realization of the research objectives. 
The researcher personally administered copies of the instrument to the sampled university graduate workers with the help of two research assistance. This ensured 99 percent returned rate. Frequency counts and percentage score were statistically techniques used to analyze the research questions.

\section{Data Analysis and Results}

The findings of the study were presented in Table 1-4 based on research questions for proper understanding.

5.1 Research question 1: In what ways do soft skills at workplace in blue economy strategy empower university output economically?

The data for analyzing this research questions were presented in Table 1.

Table 1: Soft skills as mechanism for empowerment of university output in blue economy strategy. $(\mathrm{N}=\mathbf{2 5 0})$

\begin{tabular}{|c|c|c|c|c|}
\hline $\mathrm{S} / \mathrm{N}$ & Variation sources & Agree & Disagree & Undecided \\
\hline 1. & $\begin{array}{l}\text { Soft skills had boosted multitasking } \\
\text { in human and capital resources for } \\
\text { better future. }\end{array}$ & $228(91 \%)$ & $18(7 \%)$ & $4(2 \%)$ \\
\hline 2. & $\begin{array}{l}\text { Entrepreneurship skills helped } \\
\text { university output in creativity. }\end{array}$ & $228(92 \%)$ & $9(4 \%)$ & $5(3 \%)$ \\
\hline 3. & $\begin{array}{l}\text { Life-long learming skills helped } \\
\text { university output in improving } \\
\text { domain of human. }\end{array}$ & $231(937 \%)$ & $9(4 \%)$ & $5(3 \%)$ \\
\hline 4. & $\begin{array}{l}\text { Leadership skills through training } \\
\text { Helped to developed analytical } \\
\text { Thinking and team work. }\end{array}$ & $227(90 \%)$ & $15(6 \%)$ & $8(4 \%)$ \\
\hline
\end{tabular}

The Table 1 revealed that university output soft skills have developed the three domains of human beings namely cognitive, affective and psychomotor. The university graduates were empowered through proper interaction and teamwork towards greater productivity in service and logistic sectors of the state economy. Also, there were multitasking and leveraging in the large maritime territory of Cross River State, Nigeria in order to grow fish and port industries.

5.2 Research question 2: How does blue economy strategy contributes to the sustainable development in Cross River State, Nigeria?

The data for analyzing research questions 2 were presented in Table 2.

Table 2: Blue economy strategy as an approach to sustainable development. ( $\mathrm{N}=\mathbf{2 5 0})$

\begin{tabular}{lllcc}
\hline S/N & Variation sources & Agree & Disagree & Undecided \\
\hline 5. & $\begin{array}{l}\text { New employment and capacities had } \\
\text { been created for university output. }\end{array}$ & $221(88 \%)$ & $23(9 \%)$ & $6(2 \%)$ \\
6. $\quad \begin{array}{l}\text { University output had been committed } \\
\text { to entrepreneurship in new areas of Small } \\
\text { and Medium Enterprises (SMEs). }\end{array}$ & $173(69 \%)$ & $76(30 \%)$ & $1(1 \%)$ \\
7. $\quad \begin{array}{l}\text { Coastal economics of the state received } \\
\text { a boost. }\end{array}$ & $202(81 \%)$ & $43(17 \%)$ & $5(2 \%)$ \\
8. $\quad \begin{array}{l}\text { Interconnectedness of the region economy } \\
\text { for capital accommodation. }\end{array}$ & $185(74 \%)$ & $24(10 \%)$ & $41(6 \%)$ \\
\hline
\end{tabular}


The findings presented in Table 2 with high percentage scores affirming the fact that blue economy strategy is a maritime-based economic developmental approach for sustainable development in the state. From the rating of the respondents, it created the attention of the researcher in a sense that blue economy strategy employed an environmental sustainable principles (Simmon, 2015). Hence, the focus by university management for innovations and economic growth in order to enhance the people's welfare in a holistic manner.

5.3 Research question 3: Does government contribution of university output soft skills impact economically on blue economy strategy?

The result of research question 3 was presented in Table 3 .

Table 3: Respondents' rating of government economic contribution of soft skills on blue economy benefit-related factors. $(\mathrm{N}=\mathbf{2 5 0})$

\begin{tabular}{lllll}
\hline S/N & Blue economy benefit-related factors & Strong & Moderate & Weak \\
\hline 9. & Knowledge creation. & $49(20 \%)$ & $117(47 \%)$ & $84(33 \%)$ \\
10. & Job creation. & $112(45 \%)$ & $92(37 \%)$ & $46(18 \%)$ \\
11. & Capital accumulation. & $121(48 \%)$ & $86(35 \%)$ & $43(17 \%)$ \\
12. & Environmental sustainable. & $103(41 \%)$ & $100(40 \%)$ & $47(19 \%)$ \\
\hline
\end{tabular}

The result in Table 3 depicted that capital accumulation $(48 \%)$ had the highest impact on the blue economy strategy. This was followed by job creation (45\%), environmental sustainability (41\%) and knowledge creation $(20 \%)$ which had the least impact. This had proved that above all the benefitrelated factors, the vital focus point of blue economy growth was the flow of financial capital into the domestic capital formation by government. This is to stimulate the economy towards equitable income distribution and sustainable development in the state. Also, the was a low level awareness of the benefit-related factors by the university output following the uncommitted attribute of government in enforcing maritime-based development policies. Knowledge creation did not have a strong impact according to the rating of the respondents.

\section{Discussion}

The analysis of the research question one showed that knowledge creation and soft skills of the university output relate to and interact with others. The soft skills played the role of not only developing the graduates economically, but also encouraged teamwork and multitasking in human and capital resources. This means that university education yielded meaningful learning in the graduates in authentic and intentional manner. The soft skills empowered them to set clear goals, reflect on achievements and applied learning to new situations in the future. This outcome is probably owing to the fact that soft skills helped university output to work smartly and achieve good success. The structural and complex problems in blue economy involved personal attributes which indicated high level of emotional intelligence. The findings was in consonance with Griffith (2010) which reported different mix of skills and experience as being critical at workplace, depending on the nature of business involvement. Affective learning of the university output enable them acquire soft skills for problem solving.

The university output enjoyed economic benefits through their personal knowledge and social skills of entrepreneurship, life-long learning and leadership in the coastal and state economies of Cross River State, Nigeria. This further confirmed the findings of Tsang (2013) that university education had the capacity to yield economic benefits both to individuals and the society. In Psacharopoulos (1985), such educational benefits to university graduate workers yielded rates of 
returns to education higher than physical capital investment. The low level of knowledge creation revealed the difficulties university output had in adding developmental values through scientific knowledge (Babalola, 2011). The low exhibition of traits to the soft skills by workers in the state could be reviewed as incomplete contract since labour market places higher social values on professional skills with accruing benefits from education (Hills and Rex, 2015).

This result of the analysis in Table 2 showed that the blue economy was capable of contributing to the productivity of the state dwellers and the economic level of Cross River State, Nigeria. The plausible explanation to this findings was that the blue economy employed a dynamic environmental sustainable principles which improved the economic stand (Simmon, 2015). The application of the environmental education to the development of the graduate workers yielded change in their lives and develop the totality of their mind for better future. This was in relation to new employment, innovations and increased production in logistic and other port industries for human welfare.

Blue economy strategy encompassed economic and socio-political structures whose policies exerted changes on organizations of physical settings. This produces small and medium scale businesses which could earn foreign exchange and domestic capital accumulation. These revenue yielding sources promoted potential and foreign investment, and reduced the dependence on oil in Nigeria revenue (Ekanem, 2014).

In Table 3, the finding revealed that capital accumulation factor had the benefit rated impact on the blue economy strategy than the other three factors. This was due to the direct close relationship between the graduate workers' productivity and the real income per worker. The university output at workplace gained more stock of capital goods in order to enhance their productivity. Also, this motivating impact had the possibility of increasing the ratio of investment to Gross Domestic Product (GDP) of the state. The implication of this was that the state stood to gain more if capital accumulation could increase faster than the state population growth rate for margin of saving to propel further capital formation (Ekanem, 2016 and Ekpo, 2017). Thus, capital accumulation could feed on itself.

The finding further revealed that the graduates at workplace refrained from consumption in favour of investment spending in order to absorb resources in the production of capital goods. This result supported the report in Ekanem (2014) that low domestic outputs of a developing nation often result in lower total absolute volume of savings comparative to advanced nations. In this study, increase savings and investment promoted development and prevented significant capital flight from the state. The university graduates explored and exploited business opportunities created in blue economy strategy for good living, better increase in status as well as creating invisible handshake through stimulation of other sectors of the economy. Human capital interacted with other key variables in the causal chain of growth and development. This was possible despite government uncommitted attitude to promote significantly policies on marine-based development especially in other benefit-related factors such as knowledge creation, job creation and environmental sustainability.

\section{Conclusion}

The study investigated university output soft skills at workplace in blue economy strategy for sustainable development in Cross River State, Nigeria. The study revealed that university output soft skills were beneficiary to university graduate workers in multitasking and greater productivity. Blue economy strategy could boosts new employment, innovations and enhance the welfare of the state if dynamic environmental sustainable principles were applied. Government at state and federal level contributed more on capital accumulation and less in knowledge creation, job creation and environmental sustainability. There was a financial capital flow into domestic capital formation in order to stimulate the states economy toward equitable income distribution and sustainable development. However, the uncommitted attitude of government to knowledge creation made it difficult for university output skills to promote developmental values through scientific knowledge. 
Also, poor attention of government in job creation and environmental sustainability accounted to low economic stand of the state. Hence, the study has been able to establish that there was a wide gap between knowledge creation and sustainable development as a result of university output soft skills at workplace in blue economy in Cross River State of Nigeria. The University Management had obviously not realized the potency of economics of education as an agent of education-economy and skills for development of resources and sound social living. Effective Management of university output soft skills at workplace in blue economy strategy could guarantee sustainable development in Cross River State, Nigeria

\section{Recommendations}

Based on the finding of this study, the following recommendations were made:

1. There should be adequate planning of university curriculum to ensure re-orientation for soft skills acquisition by university output as ingredient for labour-market globally. This will improve Human Development Index (HDI) and stimulate blue growth in the economy of Cross River State, Nigeria.

2. University Management should pay greater attention to promote scholarship and quality learning to thrive in university education performance. This is because Knowledge Economy Index (KEI) is needed in the state to drive the economic growth to sustainable development.

3. Government should establish legitimacy of social environment to cater for increasing number of university output with poor soft skills in the state. This is necessary because undeveloped minds of fraudulent are rotten minds, but new ideas can surmount issues in logistic and other port industries for sustainable development of the State.

4. Financial institutions and other corporate organizations should join hands to invest in blue economy. This will not only improve on foreign exchange and domestic capitals accumulations, but also create invisible handshake through stimulations of other sectors of the economy in Cross River State of Nigeria.

\section{References}

Babalola, J. B. (2011). World bank support for Nigerian Higher Education: pleasure, pains and pathways towards a knowledge Economy. An inaugural Lecture delivered at the University of Ibadan, April 4.

Ekanem, E. E. (2014) university teachers' demographic characteristics as determinats of transformed human capital development in universities in Rivers State of Nigeria. International Journal of academic research in business and social science 4 (2), 482-492

Ekanem, E. E. (2015). Staff personnel management towards technical and vocational education: Management implications for university graduates employability in Cross River State, Nigeria. Educational Journal of training and development studies, 2(1), 1-9.

Ekanem, E. E. (2016). Managing diversification of university education for poverty alleviation among university output in Cross River State, Nigeria. InternationalJournal of innovative education research 4(1), $17-25$

Ekpo, A. H. (2016). Creating a new logic and vision for Nigeria's economic development. Retrieved from www.bsjournal.com on August 12, 2016.

Ekpo A. H. (2017). Much ado about Nigeria's recovery and growth? Retrieved from www.bsjournal.com on July 25, 2017.

Friendman, T. B. (2006). Learning the soft skill of leadership. Industrial and commercial training, 37(1), 45-51.

Griffth, S. O. (2010). The basis of competence: skill development during the transition from university to work. Management learning 4(3), $210-221$.

Hills, M. N. and Rex, F. K. (2015). Skills development in higher education and employment. Journal of higher education 21(2) $121-138$.

Simmon, S. P. (2015). Economic of development, planning and public finance; London Royal publications.

Obanya, P. (2013). Education in Nigeria; The impact of bad politics and a blueprint for progress. A lecture delivered at LIDC annual lecture, January, 27.

Psacharopoulos, C. (1985). Private education in a poor country. London: Routledge. 
Tsang, S. U. (2013). Driving a revolution in university education leadership imperatives forsubstainable relevance. Environmental science and policy journal 4(2), 12-21

United Nations Development Programme (UNDP) (2010). Human development report. Retrieved from www.undp/hdr2010/pdr/HDRo3-PKE-mdggoals on November 10, 2011.

United Nations Development Programme (UNDP) (2012). Educating the next wave of Entrepreneurs.Washington DC: UNDP.

Uwadike, O. (2015). Information and communication Technology and learning experiences: Review of curriculum in science education. African Journal of theory and practical in education 2 (2), 91 - 99.

Vishal, J. (2016). Importance of soft skills development in education. Retrieved from http//ro.eco.edu.au.cedu.comon February 17, 2017.

Wilken, P. J. (2015). Employability skills development in higher education. Retrieved from www.willlearning.comon November 12, 2016. 